\title{
Smartphone and medical application use among dentists in China
}

\author{
Chao Zhang ${ }^{1,2,3}$, Lin Fan ${ }^{1,2,3}$, Zhaowu Chai ${ }^{1,2,3}$, Cong $Y u^{1,2,3}$ and Jinlin Song ${ }^{1,2,3^{*}}$ (D)
}

\begin{abstract}
Background: With the development of information technology, an increasing number of healthcare professionals are using smartphones and mobile medical applications (apps) in their clinical practice. The objective of this study was to survey the use of smartphone-based medical apps among dentists in China and determine dentists' perceptions of such apps.

Methods: All data were collected using anonymous questionnaires. The questionnaires for this cross-sectional study were randomly sent to dentists by email, and 379 dentists responded. Dentists' demographics and perceptions of WeChat, QQ (the most popular social media apps in China) and other medical apps were assessed; the questionnaire including questions on the purpose, frequency, daily use, and opinion of the apps they used. Questions were answered using a Likert scale ( $1=$ strongly agree, $2=$ agree, $3=$ not sure, $4=$ disagree, and $5=$ strongly disagree).

Results: A total of 379 valid responses were received; the respondents had a median age of 33.6 years old (63.3\% female). All subjects (100\%) owned a smartphone, and all of them installed and used WeChat or QQ in their clinical practice. Only $76 \%$ of subjects installed medical apps (other than WeChat and QQ) on their smartphones. Male dentists were more likely to install medical apps than female dentists $(p<0.05)$. With increasing age, the percentage of dentists who installed medical apps decreased $(p<0.001)$. The frequency and daily use were higher for WeChat and QQ than for medical apps. Medical apps were positively perceived, with dentists reporting that they recommend these medical apps to their peers (Likert score: 1.67 \pm 0.68 ).
\end{abstract}

Conclusion: Medical apps were perceived to have a positive impact on clinical practice, education and patient care in dentistry by providing relevant medical information. However, there will still be much room for improvement in the future.

Keywords: Smartphone, Medical applications, Dentistry, China, Dentists

\section{Background}

With the development and decreasing costs of information technology, an increasing number of people are becoming internet users worldwide. Data show that the number of internet users in the world was nearly 4,536, 248,808 by June 30,2019 [1]. There are $2,300,469,859$

\footnotetext{
* Correspondence: songjinlin@hospital.cqmu.edu.cn

${ }^{1}$ College of Stomatology, Chongqing Medical University, Chongqing, China

${ }^{2}$ Chongqing Key Laboratory for Oral Diseases and Biomedical Sciences, Chongqing, China

Full list of author information is available at the end of the article
}

internet users in Asia, representing $54.2 \%$ of the world. To date, mobile devices (such as mobile smartphones and tablets) are the main tools for accessing the internet. Smartphones have become handheld computers rather than mobile communication devices because of their powerful computing function, spacious memories, large screens and open operating systems. The tremendous improvements of smartphones has encouraged the development of various third-party applications (apps) that can be used on smartphones [2-5]. An app is a small specialized and customizable program that can provide

C The Author(s). 2020 Open Access This article is licensed under a Creative Commons Attribution 4.0 International License, which permits use, sharing, adaptation, distribution and reproduction in any medium or format, as long as you give appropriate credit to the original author(s) and the source, provide a link to the Creative Commons licence, and indicate if changes were made. The images or other third party material in this article are included in the article's Creative Commons licence, unless indicated otherwise in a credit line to the material. If material is not included in the article's Creative Commons licence and your intended use is not permitted by statutory regulation or exceeds the permitted use, you will need to obtain permission directly from the copyright holder. To view a copy of this licence, visit http://creativecommons.org/licenses/by/4.0/ The Creative Commons Public Domain Dedication waiver (http://creativecommons.org/publicdomain/zero/1.0/) applies to the data made available in this article, unless otherwise stated in a credit line to the data. 
various functions and services for users. There are numerous apps, including medical apps, available for use on smartphones. In addition to the general public, an increasing number of healthcare professionals are using medical apps in their clinical practice [2]. In the current information society, medicine has undergone remarkable advancements. Many studies have surveyed the use of smart devices or medical applications among physicians [6-8]. In dental fields, we only found similar studies on the use of medical applications or mobile learning technology among dental students around the world [9-12]. However, such research in dentists is limited, especially in China.

From the data available regarding the number of internet users worldwide it is reasonable to assume that Asia (especially China) will be a large market for smartphones and applications. Therefore, the aim of our study was to examine the current use of smartphone-based medical apps among dentists in China and determine the dentists' attitudes toward these apps. We aimed to provide readers with a better understanding of (1) the popularity of smartphones and medical apps among dentists in China, (2) the factors influencing dentists' use of medical apps, and (3) dentists' purposes for using such medical apps and attitudes towards them. With the data from this study, we hope computer scientists or dental healthcare professionals can design, improve and develop more convenient and useful smartphone-based applications according to current dentists' opinions. We also hope to help the dentists who have not used medical apps to select the proper apps to assist their clinical work.

\section{Related work}

Many studies conducted surveys regarding the use of smart devices or medical applications among physicians or medical students (Table 1). The aim of this study was to survey the use of smartphone-based medical apps among dentists in China and determine the dentists' perceptions of such apps.

In 2012, Orrin et al. performed a prospective, nationwide email survey evaluating the use of smartphones and smartphone apps among providers at medical centers recognized by the Accreditation Council for Graduate Medical Education (ACGME) in the United States of America (USA) [8]. A total of 3306 unique responses from 1397 residents, 524 fellows, and 1385 attending physicians were received in the study. Greater than $85 \%$ of respondents used a smartphone. Over half of the respondents reported using apps in their clinical practice. The most commonly used app types were drug guides, medical calculators, coding and billing apps and pregnancy wheels.

Karl et al. conducted an online survey on smartphoneand medical-related app use among medical students and junior doctors in the United Kingdom (UK) in 2012 [11]. A total of $79.0 \%$ of medical students and $74.8 \%$ of junior doctors owned a smartphone. On average, apps were used for between 1 and $30 \mathrm{~min}$ per $24 \mathrm{~h}$ for students and 1-20 min per $24 \mathrm{~h}$ for doctors.

In 2018, Rikesh et al. assessed smartphone use among UK surgical doctors [7]. A total of 341 participants were surveyed. A total of $93.5 \%$ of participants owned a smartphone, with $54.2 \%$ of those owning medical apps and $86.2 \%$ using their device to access online medical resources. A total of $79.3 \%$ stated that they would be willing to use their smartphone for clinical use.

Payal et al. performed an assessment of digital literacy and the use of smart phones among Central Indian dental students [13]. Out of 260 students, 250 were internet users. A total of $94.23 \%$ of students owned a smartphone, and $46.53 \%$ of students had at least one app related to dentistry on their smartphone device. A total of $89.23 \%$ of students were keen for the implementation of e-learning in their curriculum.

\section{Methods}

\section{Questionnaire and procedures}

Considering that WeChat and QQ are the most popular social media apps in China, we investigated their use in dental clinical practice separately. The medical apps investigated in our study were a series of apps that are associated with clinical practice (other than WeChat and QQ).

The study questionnaire consisted of several parts (supplementary files). Part 1 collected dentists' demographic data, including age, gender, workplace, medical rank, whether a smartphone was used, and brand of smartphone. Part 2 investigated the use of WeChat and QQ in dentists' clinical work, including whether or not they used WeChat and QQ for work-related activities, and the purpose, frequency and daily use time of these apps. Part 3 surveyed the use of medical apps in dentists' clinical work, including whether medical apps were installed, how many apps were installed, and the purpose, frequency and daily use time of these medical apps. Part 4 assessed the dentists' perceptions of smartphone-based medical apps. Part 5 assessed the impact of medical apps on clinical practice. Responses to questions in parts $4-5$ were based on a 5point Likert scale: $1=$ strongly agree, $2=$ agree, $3=$ not sure, $4=$ disagree, and $5=$ strongly disagree.

The questionnaire was sent to 1500 dentists by email; we received 390 replies (response rate of 26\%). The questionnaire was reviewed by an expert panel for content validity and reliability. Eleven dentists only responded to the questions in part 1 , so we did not include their questionnaires in the analysis. Of the remaining 379 subjects, 91 dentists expressed that they did not install any medical apps except WeChat or QQ, and they did not answer the questions in part 4 and part 
Table 1 Previous works

\begin{tabular}{llll}
\hline Name & $\begin{array}{l}\text { Research } \\
\text { object }\end{array}$ & Country & Objective \\
\hline $\begin{array}{l}\text { Orrin } \\
\text { et al. }\end{array}$ & $\begin{array}{l}\text { Medical } \\
\text { providers }\end{array}$ & USA & $\begin{array}{l}\text { The use of smartphones and smartphone apps among } \\
\text { providers at medical centers recognized by the } \\
\text { Accreditation Council for Graduate Medical Education }\end{array}$ \\
{$[8]$} & & (ACGME)
\end{tabular}

Result

1. A total of 3306 unique responses from 1397 residents, 524 fellows, and 1385 attending physicians among 27 different specialties attended the Study. 2. Greater than $85 \%$ of respondents used a smartphone.

3. Over half of the respondents reported using apps in their clinical practice.

4. the most commonly used app types were drug guides, medical calculators, coding and billing apps and pregnancy wheels.

$\begin{array}{llll}\text { Karl } & \text { Medical } & \text { United } & \text { Smartphone and medical related App use among medical } \\ \text { et al. } & \text { students, } & \text { Kingdom } & \text { students and junior doctors } \\ (2012) & \text { junior } & & \\ {[11]} & \text { doctors } & & \end{array}$

1. 257 medical students and 131 junior doctors attended the study.

2. $79.0 \%$ of medical students and $74.8 \%$ of junior doctors owned a smartphone.

3. The majority of students and doctors owned 1-5 medical related applications, with very few owning more than 10.

4. Over $24 \mathrm{~h}$ apps were used for between 1 and 30 min for students and 1-20 min for doctors.

5. Students used disease diagnosis/management and drug reference apps, with doctors favouring clinical score/calculator apps.

Rikesh Surgical United Smartphone use amongst doctors within the surgical et al. doctors Kingdom profession

(2015)

1. A total of 341 participants were surveyed.

2. $93.5 \%$ of which owned

a smartphone, with $54.2 \%$ of those owning medical apps and $86.2 \%$ using their device to access online medical resources.

3. $79.3 \%$ stated that they would be willing to use their smartphone for clinical use.

$\begin{array}{lll}\text { Payal Dental } & \text { Central } & \text { Digital literacy and use of smart phones among Central } \\ \text { et al. } & \text { students } & \text { Indian } \\ \text { Indian dental students }\end{array}$

1. Out of 260 students, 250 were internet users.

2. $94.23 \%$ students owned a smartphone.

3. $46.53 \%$ students had some app related to the dentistry in their smartphone device.

4. Nearly $80 \%$ dental students believed that social media helps them in their professional course studies. 5. $89.23 \%$ students were keen for implementation of e-learning in their curriculum. $\begin{array}{lll}\text { Sameer Physicians } & \text { Saudi } & \text { Popularity and impact of using smart devices in medicine } \\ \text { et al. } & \text { Arabia } & \text { in Saudi Arabia }\end{array}$

(2018) Saudi Arabia
1. 300 physicians attended the study.

2. $88.3 \%$ physicians had smart devices, and $86.3 \%$ had at least one medical app installed.

3. 53.0\% used an app at least once a day.

4. Medical apps were positively perceived, with physicians reporting increased dependency on the apps
5. Therefore, we only analyzed the remaining 288 dentists' perceptions of these medical apps. The flow diagram outlining the collection of eligible questionnaires for this study is shown in Fig. 1.

\section{Statistical analysis}

Data were analyzed using SPSS statistical software (version 17, SPSS, Inc., Chicago, IL, USA). Subject characteristics are presented as frequencies (percentages). Quantitative Likert scale data are presented as the mean \pm standard deviation. A chi-square test was used to examine the difference in owning a medical app among different groups. A $p$ value of $<0.05$ was considered significant.

\section{Results}

Demographic characteristics of surveyed dentists in China A total of 379 valid responses were received. The median study subject age was 33.6 years old (range: 19-59 years old), and $240(63.3 \%)$ subjects were female. A total of $168(44.3 \%)$ subjects worked in public hospitals, and 211 (55.7) subjects worked in private hospitals or clinics. Additionally, $47.2 \%$ of subjects were resident dentists, $40.4 \%$ were dentists in charge, and $12.4 \%$ were senior or associate senior dentists. All subjects (100\%) owned a smartphone. The most popular brands of smartphones were Apple (46.2\%) and Huawei (34\%, Table 2).

\section{The use of WeChat or QQ in dentists' clinical work} All participants installed WeChat or QQ on their smartphones, and they all used WeChat or QQ in their 


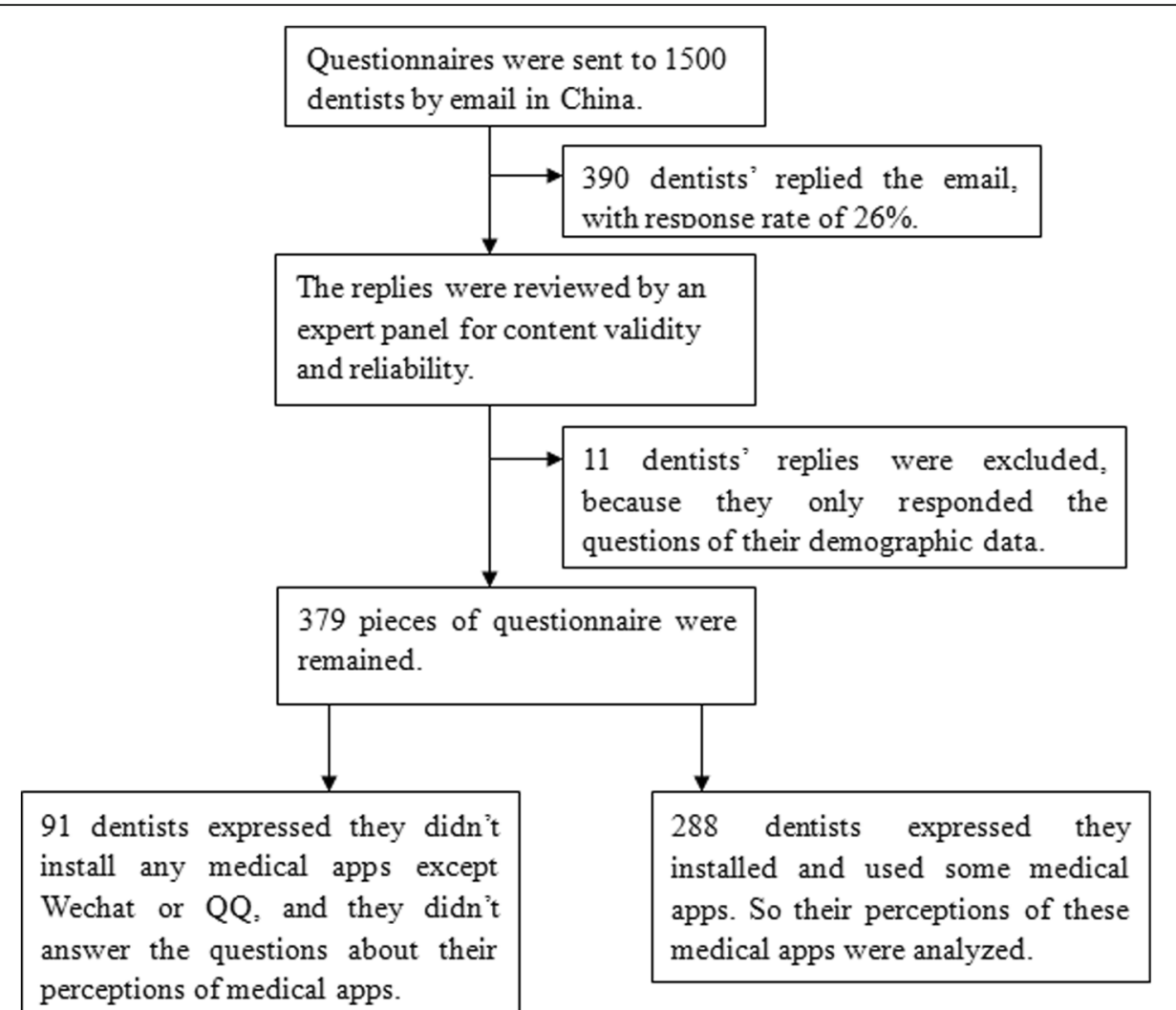

Fig. 1 Trial Flow Diagram. This figure presents the trial flow diagram of collecting eligible questionnaires for this study

clinical practices. Participants reported that their main purposes for using WeChat or QQ in clinical practice were acquiring medical information (84.2\%), communicating with peers $(83.6 \%)$ and communicating with patients (77.6\%). The frequency of using WeChat or QQ in clinical practice was reported to be at least once a day (73.6\%), at least once a week (20.8\%), or less than once a month $(5.5 \%$, Table 3$)$. The time of daily usage is shown in Table 3; $25.9 \%$ subjects used WeChat or QQ in their clinical practice for more than 60 min per day, 19\% subjects reported their daily use time was $21-30 \mathrm{~min}, 17.4 \%$ subjects reported their daily use time was $11-20 \mathrm{~min}$.

\section{The use of medical apps in dentists' clinical work}

A total of $288(76 \%)$ subjects had medical apps (other than WeChat and QQ) installed on their smartphones, and $91(24 \%)$ subjects did not have any medical apps installed, as shown in Table 4. Male dentists were more likely to install medical apps than female dentists (chisquare $=6.702, p<0.05$ ). With increasing age, the percentage of dentists who had medical apps installed decreased (chi-square $=45.3 .3, \quad p<0.001$ ). However, dentists' workplace and medical rank were not significantly associated with the installation of medical apps (chi-square $=1.670, \quad p=0.196 ; \quad$ chi-square $=5.466, \quad p=$
0.065 , respectively, Table 5). Among the 288 subjects, the average number of medical apps installed was $2.62 \pm$ 1.73 (range: 1-12). Most subjects (71.5\%) reported that they had 1-5 medical apps installed on their smartphones, and only $0.5 \%$ of subjects had more than 10 medical apps installed on their smartphones (Table 4). The frequency and daily use (in minutes) of these medical apps among dentists is shown in Table 6. A total of $46.5 \%$ of subjects used medical apps at least once a day, $42.4 \%$ of subjects used them at least once a week, and $11.1 \%$ used them less than once a month. Among those who reported daily use, most reported $11-20 \mathrm{~min}$ of usage (31.6\%) per day, followed by $11-10 \mathrm{~min}(29.2 \%)$ and $21-30 \mathrm{~min}(15.6 \%)$. Only $5.2 \%$ of subjects reported that they used medical apps more than $60 \mathrm{~min}$ per day (Table 6). The top three purposes for using medical apps were reviewing medical knowledge (63.6\%), reading medical news (36.4\%), and reading medical journals (27.9\%, Table 7).

\section{Perceptions of smartphone-based medical apps and their impacts on clinical practice}

The majority of subjects strongly agreed or agreed that they are looking to obtain more medical apps in the future $(1.52 \pm 0.69)$, that they would recommend these 
Table 2 Demographic characteristics of surveyed dentists in China ( $n=379$ subjects)

\begin{tabular}{|c|c|c|}
\hline & Number & Percent (\%) \\
\hline \multicolumn{3}{|l|}{ Age } \\
\hline$\leq 30$ & 152 & 40.1 \\
\hline $31-40$ & 181 & 47.8 \\
\hline $41-50$ & 24 & 6.3 \\
\hline$>50$ & 22 & 5.8 \\
\hline \multicolumn{3}{|l|}{ Gender } \\
\hline Male & 139 & 36.7 \\
\hline Female & 240 & 63.3 \\
\hline \multicolumn{3}{|l|}{ Workplace } \\
\hline Public hospital & 168 & 44.3 \\
\hline Private hospital or clinic & 211 & 55.7 \\
\hline \multicolumn{3}{|l|}{ Medical rank } \\
\hline Resident dentist & 179 & 47.2 \\
\hline Dentist in charge & 153 & 40.4 \\
\hline Senior/associate senior dentist & 47 & 12.4 \\
\hline \multicolumn{3}{|l|}{ Do you own a smartphone? } \\
\hline Yes & 379 & 100 \\
\hline \multicolumn{3}{|c|}{ What's the brand of your smarphone? } \\
\hline Apple & 175 & 46.2 \\
\hline Huawei & 129 & 34 \\
\hline OPPO & 33 & 8.7 \\
\hline Xiaomi & 28 & 7.4 \\
\hline Sumsung & 6 & 1.6 \\
\hline Others & 8 & 2.1 \\
\hline
\end{tabular}

medical apps to other peers $(1.67 \pm 0.68)$, that medical apps are essential tools for undergraduate medical studies $(1.91 \pm 0.78)$, and that medical apps supplement medical textbooks $(1.83 \pm 0.64)$. Regarding whether medical apps are superior to medical textbooks $(3.16 \pm 0.81)$ or whether medical apps can replace medical textbooks $(3.31 \pm 0.94)$, the majority of subjects reported disagreement or that they were not sure. A total of $46.2 \%$ of subjects agreed that there are dangers in using medical apps for patient care, and $39.6 \%$ of subjects were not sure about this question $(2.61 \pm 0.73$, Table 8$)$.

The majority of subjects agreed that medical apps could improve clinical decision making (2.30 \pm 0.77$)$, save time $(2.11 \pm 0.68)$, help in making differential diagnoses $(2.56 \pm 0.74)$, and perform useful medical-related calculations $(2.52 \pm 0.77)$. Additionally, medical apps were thought to be beneficial for allowing faster access to evidence-based medical practices/cases $(2.34 \pm 0.80)$; they were reported to be reliable sources of clinical skills $(2.25 \pm 0.67)$, medical knowledge $(2.19 \pm 0.68)$, common laboratory reference values $(2.30 \pm 0.65)$, and medical information $(1.90 \pm 0.54$, Table 9$)$.
Table 3 The use of Wechat or QQ in dentists' clinical work $(n=$ 379 subjects)

\begin{tabular}{|c|c|c|}
\hline & Number & Percent (\%) \\
\hline \multicolumn{3}{|c|}{ Have you installed Wechat or QQ on your smartphone? } \\
\hline Yes & 379 & 100 \\
\hline \multicolumn{3}{|c|}{ Do you use WeChat or QQ in clinical practice? } \\
\hline Yes & 379 & 100 \\
\hline \multicolumn{3}{|c|}{ The purpose for using WeChat or QQ in clinical practice } \\
\hline Communicating with patients & 294 & 77.6 \\
\hline Communicating with peers & 317 & 83.6 \\
\hline Acquiring medical information & 319 & 84.2 \\
\hline Others & 76 & 20 \\
\hline \multicolumn{3}{|c|}{ Frequency of using WeChat or $\mathrm{QQ}$ in clinical practice } \\
\hline At least once a day & 279 & 73.6 \\
\hline At least once a week & 79 & 20.8 \\
\hline Less than once a month & 21 & 5.5 \\
\hline \multicolumn{3}{|c|}{$\begin{array}{l}\text { Daily use of WeChat or } \mathrm{QQ} \text { in clinical practice within dentists (in } \\
\text { minutes) }\end{array}$} \\
\hline None & 0 & 0 \\
\hline $1-10 \mathrm{~min}$ & 51 & 13.5 \\
\hline $11-20 \mathrm{~min}$ & 66 & 17.4 \\
\hline $21-30 \mathrm{~min}$ & 72 & 19 \\
\hline $31-40 \mathrm{~min}$ & 49 & 12.9 \\
\hline $41-50 \mathrm{~min}$ & 24 & 6.3 \\
\hline $51-60 \mathrm{~min}$ & 19 & 5.0 \\
\hline$>60 \min$ & 98 & 25.9 \\
\hline
\end{tabular}

\section{Discussion}

In recent decades, the technologies of mobile communication, mobile wireless internet and mobile devices have been widely used in many areas of human life. In this context, customized and multifunctional mobile apps (including medical apps) have flourished tremendously. Studies have shown that an increasing number of medical staff installed medical apps on their smart devices (including smartphones and tablets) and used them

Table 4 The use of medical apps in dentists' clinical work $(n=$ 379 subjects)

\begin{tabular}{|c|c|c|}
\hline & Number & Percent (\%) \\
\hline \multicolumn{3}{|c|}{$\begin{array}{l}\text { Have you installed medical apps on your smartphone? (except Wechat } \\
\text { and QQ) }\end{array}$} \\
\hline Yes & 288 & 76 \\
\hline No & 91 & 24 \\
\hline \multicolumn{3}{|c|}{ How many medical apps do you have on your smartphone? } \\
\hline No & 91 & 24 \\
\hline $1-5$ apps & 271 & 71.5 \\
\hline $6-10$ apps & 15 & 4 \\
\hline$>10$ apps & 2 & 0.5 \\
\hline
\end{tabular}


Table 5 The factors of affecting whether or not dentists installed medical apps

\begin{tabular}{|c|c|c|c|c|c|c|}
\hline & \multicolumn{2}{|c|}{ Whether or not dentist installed medical apps } & \multirow[t]{2}{*}{ Total } & \multirow{2}{*}{$\begin{array}{l}\text { Chi-square } \\
\text { test }\end{array}$} & \multirow[t]{2}{*}{ df } & \multirow[t]{2}{*}{$p$-value } \\
\hline & Yes & No & & & & \\
\hline \multicolumn{7}{|l|}{ Gender } \\
\hline Male & 116 & 23 & 139 & 6.702 & 1 & 0.010 \\
\hline Female & 172 & 68 & 240 & & & \\
\hline \multicolumn{7}{|l|}{ Age } \\
\hline$\leq 30$ & 124 & 28 & 152 & 45.303 & 3 & 0.000 \\
\hline $31-40$ & 144 & 37 & 181 & & & \\
\hline $41-50$ & 16 & 8 & 24 & & & \\
\hline$>50$ & 4 & 18 & 22 & & & \\
\hline \multicolumn{7}{|l|}{ Workplace } \\
\hline Public hospital & 133 & 35 & 168 & 1.670 & 1 & 0.196 \\
\hline Private hospital or clinic & 155 & 56 & 211 & & & \\
\hline \multicolumn{7}{|l|}{ Medical rank } \\
\hline Resident dentist & 135 & 44 & 179 & 5.466 & 2 & 0.065 \\
\hline Dentist in charge & 123 & 30 & 153 & & & \\
\hline Senior/associate senior dentist & 30 & 17 & 47 & & & \\
\hline Total & 288 & 91 & 379 & & & \\
\hline
\end{tabular}

frequently [2]. However, few studies have assessed the use of such medical applications among dentists. Therefore, in this study, we first performed such research in China. By using anonymous questionnaires, we collected data on the use of smartphone-based medical apps among dentists in China.

We found that all participants (100\%) in our study owned a smartphone, and the rate was slightly higher than many other similar studies (ranging from 82 to

Table 6 The frequency and daily use (in minutes) of medical apps within dentists in China ( $n=288$ subjects)

\begin{tabular}{lll}
\hline & Number & Percent (\%) \\
\hline Frequency & & \\
At least once a day & 134 & 46.5 \\
At least once a week & 122 & 42.4 \\
Less than once a month & 32 & 11.1 \\
Daily use & & \\
None & 2 & 0.7 \\
1-10 min & 84 & 29.2 \\
11-20 min & 91 & 31.6 \\
21-30 min & 45 & 15.6 \\
31-40 min & 30 & 10.4 \\
$41-50$ min & 16 & 5.6 \\
$51-60$ min & 5 & 1.7 \\
$>60$ min & 15 & 5.2 \\
\hline
\end{tabular}

99.3\%) [14-18]. The most popular brands of smartphones were Apple and Huawei (a Chinese Android smartphone), and this result was consistent with another study [18]. All subjects had WeChat or QQ (the most popular social media applications in China) installed on their smartphones and used them in clinical practice. In 2016, Li et al. investigated the effect of WeChat on the compliance and duration of treatment in orthodontic patients in China. The authors found that use of this app

Table 7 Purpose for using smartphone based medical apps ( $n=288$ subjects)

\begin{tabular}{lll}
\hline & Number & Percent (\%) \\
\hline Reviewing medical knowledge & 241 & 63.6 \\
Reading medical news & 138 & 36.4 \\
Reading medical journals & 106 & 27.9 \\
Clinical skills guide & 105 & 27.7 \\
Communicating with patients & 98 & 25.9 \\
Communicating with colleages & 97 & 25.6 \\
Preparing presentations & 87 & 22.9 \\
Assisting diagnosis & 80 & 21.1 \\
Exam preparation & 67 & 17.7 \\
During ward rounds & 64 & 16.9 \\
Medication or drug guide & 64 & 16.9 \\
Scheduling patients' appointment & 47 & 12.4 \\
Mobile learning & 30 & 7.9 \\
\hline
\end{tabular}


Table 8 Dentists' perceptions on smartphone based medical apps ( $n=288$ subjects)

\begin{tabular}{|c|c|c|c|c|c|}
\hline & & Number & Percent (\%) & Mean & SD \\
\hline \multirow[t]{5}{*}{ Medical apps are easy to obtain } & Strongly agree & 56 & 19.4 & 2.36 & 0.99 \\
\hline & Agree & 127 & 44.1 & & \\
\hline & Not sure & 51 & 17.7 & & \\
\hline & Disagree & 54 & 18.8 & & \\
\hline & Stongly disagree & 0 & 0 & & \\
\hline \multirow[t]{5}{*}{ I am looking to obtain more medical apps in the future } & Strongly agree & 160 & 55.6 & 1.52 & 0.69 \\
\hline & Agree & 114 & 39.6 & & \\
\hline & Not sure & 5 & 1.7 & & \\
\hline & Disagree & 9 & 3.1 & & \\
\hline & Stongly disagree & 0 & 0 & & \\
\hline \multirow[t]{5}{*}{ I would recommend these medical apps to other peers } & Strongly agree & 122 & 42.4 & 1.67 & 0.68 \\
\hline & Agree & 148 & 51.4 & & \\
\hline & Not sure & 10 & 3.5 & & \\
\hline & Disagree & 8 & 2.8 & & \\
\hline & Stongly disagree & 0 & 0 & & \\
\hline \multirow[t]{5}{*}{ I do most of my medical learning using medical apps } & Strongly agree & 62 & 21.5 & 2.43 & 1.17 \\
\hline & Agree & 131 & 45.5 & & \\
\hline & Not sure & 9 & 3.1 & & \\
\hline & Disagree & 80 & 27.8 & & \\
\hline & Stongly disagree & 6 & 2.1 & & \\
\hline \multirow[t]{5}{*}{ Medical apps are essential tools for undergraduate medical studies } & Strongly agree & 91 & 31.6 & 1.91 & 0.78 \\
\hline & Agree & 140 & 48.6 & & \\
\hline & Not sure & 48 & 16.7 & & \\
\hline & Disagree & 9 & 3.1 & & \\
\hline & Stongly disagree & 0 & 0 & & \\
\hline \multirow[t]{5}{*}{ Medical apps are superior to medical textbooks } & Strongly agree & 13 & 4.5 & 3.16 & 0.81 \\
\hline & Agree & 56 & 19.4 & & \\
\hline & Not sure & 98 & 34 & & \\
\hline & Disagree & 115 & 39.9 & & \\
\hline & Stongly disagree & 6 & 2.1 & & \\
\hline \multirow[t]{5}{*}{ Medical apps can replace medical textbooks } & Strongly agree & 7 & 2.4 & 3.31 & 0.94 \\
\hline & Agree & 68 & 23.6 & & \\
\hline & Not sure & 48 & 16.7 & & \\
\hline & Disagree & 159 & 55.2 & & \\
\hline & Stongly disagree & 6 & 2.1 & & \\
\hline \multirow[t]{5}{*}{ Medical apps supplement medical textbooks } & Strongly agree & 77 & 26.7 & 1.83 & 0.64 \\
\hline & Agree & 193 & 67 & & \\
\hline & Not sure & 9 & 3.1 & & \\
\hline & Disagree & 8 & 2.8 & & \\
\hline & Stongly disagree & 1 & 0.3 & & \\
\hline \multirow[t]{4}{*}{ Medical apps provide useful point-of-care medical information } & Strongly agree & 54 & 18.8 & 2.28 & 0.97 \\
\hline & Agree & 149 & 51.7 & & \\
\hline & Not sure & 34 & 11.8 & & \\
\hline & Disagree & 51 & 17.7 & & \\
\hline
\end{tabular}


Table 8 Dentists' perceptions on smartphone based medical apps ( $n=288$ subjects) (Continued)

\begin{tabular}{lllll}
\hline & & Number & Percent (\%) & Mean \\
\hline & Stongly disagree & 0 & 0 & 2.4 \\
There are dangers in using medical apps for patient care & Strongly agree & 7 & 133 & 46.2 \\
& Agree & 114 & 39.6 \\
& Not sure & 34 & 11.8 \\
\hline
\end{tabular}

could reduce the treatment duration and bracket bond failure and improve clinic attendance in orthodontic patients [19]. Additionally, in our study, we found that $73.6 \%$ of subjects used these apps at least once a day, and only $5.5 \%$ of subjects used them less than once a month. A total of $25.9 \%$ of subjects reported that they typically used them in clinical practice more than $60 \mathrm{~min}$ per day. As we can see, the use of such social media apps (for purposed including acquiring medical information, communicating with peers and communicating with patients) is very common among dentists in China.

Only $76 \%$ of the participants $(n=288)$ installed a medical app (other than WeChat and QQ) on their smartphones. Though the rate was lower compared with the installation of WeChat and QQ, the number was still in agreement with many studies in other areas of the world $[14,15,20]$. Our study found that there were significant differences in whether medical apps were installed by gender and age. This finding was supported by many studies, in which young physicians were more likely to use medical apps than old physicians $[7,14]$. In our study, male dentists were more likely to use medical apps than females. Males are more interested in Internet technology and software in China, which could explain this observed phenomenon.

The average number of installed medical apps was 2.62, which was relatively small. According to the data regarding frequency and daily use of these medical apps, only $46.5 \%$ of subjects used medical apps at least once a day, and only $5.2 \%$ of subjects reported that they used medical apps more than $60 \mathrm{~min}$ per day. Compared with the use of WeChat or QQ in China, we found that the use of medical apps among dentists in China was not very prevalent. Compared with US and British healthcare professionals with a use rate of over $90 \%$, our sample of dentists still showed a relatively lower medical app use [21, 22].

Most of our subjects agreed or strongly agreed that they are looking to obtain more medical apps in the future and recommend these medical apps to other peers, which could reflect their affirmation and expectation towards medical apps. Most subjects agreed or strongly agreed that medical apps are essential tools for undergraduate medical studies and supplement medical textbooks. These findings were in agreement with several other studies that assessed the use of medical apps among dental students or junior doctors in many other regions around the world [9-12, 23-27]. Although dentists thought medical apps could improve education among students, they reported disagreement or uncertainty with regard to whether medical apps are superior to medical textbooks or medical apps can replace medical textbooks. Most of them agreed that there are dangers in using medical apps for patient care. As we know, the accuracy of the information in a medical app is very important. If users make their clinical decision based on inaccurate or outdated information in medical apps, there could be serious consequences. Many studies have been conducted to assess the quality and accuracy (including expert involvement and medical evidence adherence) of these medical applications in the past few years [28-34]. The expert involvement rate of these applications ranged from 9 to $67 \%$, and the adherence rate ranged from 0 to $87 \%$ [28]. Therefore, establishing appropriate regulatory procedures is extremely urgent. We believe that government health authorities (such as the Food and Drug Administration in America [35], the Medicines and Healthcare Products Regulatory Agency in England [36], Health Canada in Canada [37] and corresponding authorizes in other countries) could play a key role. To regulate these medical apps well, government health authorities could draft relevant guidelines that should be followed by app developers.

Regarding the effect of medical apps on clinical practice, dentists in China strongly agreed or agreed that these medical apps could allow faster access to medical information $(1.90 \pm 0.54)$. However, regarding the other aspects of the effect, Chinese dentists' attitudes were less positive than those reported in a similar study [14]. From the results above, we found that current medical apps in dentistry did well in providing relevant medical information in China and received positive reviews from Chinese dentists. However, on the other hand (i.e. outside of improved clinical decision making; saving time; help in making differential diagnoses; performing useful medical-related calculations; faster access to evidencebased medical practices/cases; and providing reliable sources of clinical skills, knowledge, and common laboratory reference values), medical apps did not meet the needs of dentists well. Therefore, in the future, there will be much room for improvement. 
Table 9 Perceived impact of smartphone based medical apps on clinical practice

\begin{tabular}{|c|c|c|c|c|c|}
\hline & & Number & Percent (\%) & Mean & SD \\
\hline \multirow[t]{5}{*}{ Improve clinical decision-making } & Strongly agree & 30 & 10.4 & 2.30 & 0.77 \\
\hline & Agree & 166 & 57.6 & & \\
\hline & Not sure & 67 & 23.3 & & \\
\hline & Disagree & 25 & 8.7 & & \\
\hline & Stongly disagree & 0 & 0 & & \\
\hline \multirow[t]{5}{*}{ Save time } & Strongly agree & 41 & 14.2 & 2.11 & 0.68 \\
\hline & Agree & 185 & 64.2 & & \\
\hline & Not sure & 51 & 17.7 & & \\
\hline & Disagree & 11 & 3.8 & & \\
\hline & Stongly disagree & 0 & 0 & & \\
\hline \multirow[t]{5}{*}{ Allow faster access to medical information } & Strongly agree & 53 & 18.4 & 1.90 & 0.54 \\
\hline & Agree & 214 & 74.3 & & \\
\hline & Not sure & 17 & 5.9 & & \\
\hline & Disagree & 4 & 1.4 & & \\
\hline & Stongly disagree & 0 & 0 & & \\
\hline \multirow[t]{5}{*}{ Allow faster access to common laboratory reference values } & Strongly agree & 16 & 5.6 & 2.30 & 0.65 \\
\hline & Agree & 185 & 64.2 & & \\
\hline & Not sure & 72 & 25 & & \\
\hline & Disagree & 15 & 5.2 & & \\
\hline & Stongly disagree & 0 & 0 & & \\
\hline \multirow[t]{5}{*}{ Help in developing differential diagnoses } & Strongly agree & 7 & 2.4 & 2.56 & 0.74 \\
\hline & Agree & 176 & 61.1 & & \\
\hline & Not sure & 70 & 24.3 & & \\
\hline & Disagree & 35 & 12.2 & & \\
\hline & Stongly disagree & 0 & 0 & & \\
\hline \multirow[t]{5}{*}{ Perform useful medical related calculations } & Strongly agree & 8 & 2.8 & 2.52 & 0.77 \\
\hline & Agree & 163 & 56.6 & & \\
\hline & Not sure & 78 & 27.1 & & \\
\hline & Disagree & 38 & 13.2 & & \\
\hline & Stongly disagree & 1 & 0.3 & & \\
\hline \multirow[t]{5}{*}{ Allow faster access to reliable sources of medical knowledge } & Strongly agree & 28 & 9.7 & 2.19 & 0.68 \\
\hline & Agree & 194 & 67.4 & & \\
\hline & Not sure & 50 & 17.4 & & \\
\hline & Disagree & 16 & 5.6 & & \\
\hline & Stongly disagree & 0 & 0 & & \\
\hline \multirow[t]{5}{*}{ Allow faster access to reliable sources of clinical skills } & Strongly agree & 24 & 8.3 & 2.25 & 0.67 \\
\hline & Agree & 180 & 62.5 & & \\
\hline & Not sure & 71 & 24.7 & & \\
\hline & Disagree & 13 & 4.5 & & \\
\hline & Stongly disagree & 0 & 0 & & \\
\hline \multirow[t]{5}{*}{ Allow faster access to evidence-based medical practice/case } & Strongly agree & 39 & 13.5 & 2.34 & 0.80 \\
\hline & Agree & 132 & 45.8 & & \\
\hline & Not sure & 96 & 33.3 & & \\
\hline & Disagree & 21 & 7.3 & & \\
\hline & Stongly disagree & 0 & 0 & & \\
\hline
\end{tabular}




\section{Conclusion}

In conclusion, the use of smartphones and some social media apps (WeChat or QQ) is very common among dentists in China. The use of medical apps is also prevalent. These medical apps received positive reviews because most dentists reported that they would want to obtain more medical apps in the future and recommend these medical apps to other peers. These medical apps could allow dentists faster access to medical information in their clinical practices. However, there is still much room for improvement in patient care in the future (such as assisting with diagnoses and determining treatment options).

According to this study, we found that there are many advantages of medical apps, including reviewing medical knowledge, reading medical or journals, acquiring clinical skills, communicating with patients/colleagues, and preparing presentations or examinations. In general, medical apps could be a good assistant for dentists in clinical practice. We believe that there will be an increasing number of dentists using medical apps in the future. Of course, patients would also benefit from these apps. However, there are still some disadvantages or risks of medical apps, such as data security, virus attack, inaccurate content, and lack expert involvement, to which we should pay attention. Therefore, establishing appropriate regulatory procedures is extremely important. We think the following tips could help [38]. First, the app stores should carefully examine any medical apps that would like to be published online. Second, the content and information in medical apps should be peer reviewed by relevant medical professionals. Third, a reliable assessment system or method for these medical applications should be established. An assessment or score of medical apps could help users select more appropriate apps for their purposes. Finally, we think the involvement of government health authorities is most important. We believe that the risks of using medical apps could be reduced by following these methods.

\section{Limitations}

There were some limitations in our study. First, our sample size was relatively small. We need a larger sample size to confirm our findings on medical app use among dentists in China in the future. Nevertheless, our results are in agreement with many similar studies conducted in other regions around the world and provide preliminary information. Second, our study only examined dentists' perceptions of medical apps. Further studies should be conducted to examine dental patients' use and perceptions of medical apps to examine how medical apps affect their oral healthcare. Third, our study did not investigate the potentially negative impacts of medical app use. Because the issue of patient safety and privacy has been proposed in recent years, we should focus on these issues in further investigations.

\section{Supplementary information}

Supplementary information accompanies this paper at https://doi.org/10. 1186/s12911-020-01238-3.

\section{Additional file 1.}

Additional file 2.

Additional file 3.

\section{Abbreviations}

Apps: Applications; ACGME: Accreditation Council for Graduate Medical Education; USA: United States of America; UK: United Kingdom

\section{Acknowledgements}

The authors thank colleagues in Stomatological Hospital of the Chongqing Medical University for their work in sending emails of questionnaire to our subjects.

\section{Authors' contributions}

Song and Zhang contributed to the study conception and design. Material preparation were performed by Zhang, data collection were performed by Fan and Chai, data analysis were performed by Zhang and Yu. The first draft of the manuscript was written by Zhang and all authors commented on previous versions of the manuscript. All authors read and approved the final manuscript.

\section{Funding}

This study was supported by the Program for Innovation Team Building at Institutions of Higher Education in Chongqing in 2016 (NO

CXTDG201602006), Natural Science Foundation of Chongqing, China in 2018 (Grant No: cstc2018jscx-mszdX0017), Oral Disease Prevention and New Materials, Shanxi Provincial Key Laboratory Open Project (No: KF2020-01).

\section{Availability of data and materials}

You could find the date in additional supporting files.

\section{Ethics approval and consent to participate}

The study was performed according to the World Medical Association's Declaration of Helsinki, and the procedures were approved by the ethics committees of the Stomatological Hospital of the Chongqing Medical University (2019-79). The study did not involve any medical examination, surgical procedure, or collection of personal health information. Therefore, completing and returning the questionnaire was considered as provision of informed consent to participate in the study.

Consent for publication

Not applicable.

\section{Competing interests}

None of the authors have any relevant financial relationship(s) with a commercial interest.

\section{Author details}

${ }^{1}$ College of Stomatology, Chongqing Medical University, Chongqing, China. ${ }^{2}$ Chongqing Key Laboratory for Oral Diseases and Biomedical Sciences, Chongqing, China. ${ }^{3}$ Chongqing Municipal Key Laboratory of Oral Biomedical Engineering of Higher Education, Chongqing, China.

Received: 18 June 2020 Accepted: 2 September 2020

Published online: 07 September 2020

\section{References}

1. Internet Word Stats. World Internet Users and 2019 Population Stats. [https://www.internetworldstats.com/stats.htm]. Accessed 2 Jan 2020.

2. Mosa AS, Yoo I, Sheets $L$. A systematic review of healthcare applications for smartphones. BMC Med Inform Decis Mak. 2012;12(1):67-97.

3. Boulos MN, Wheeler $S$, Tavares $C$, et al. How smartphones are changing the face of mobile and participatory healthcare: an overview, with example from eCAALYX. Biomed Eng Online. 2011;10:24-37. 
4. Baheti MJ, Toshniwal N. Orthodontic apps at fingertips. Prog Orthod. 2014; 15(1):36-40.

5. Franko Ol. Smartphone apps for orthopaedic surgeons. Clin Orthop Relat Res. 2011:469(7):2042-8.

6. Ozdalga E, Ozdalga A, Ahuja N. The smartphone in medicine: a review of current and potential use among physicians and students. J Med Internet Res. 2012;14(5):e128.

7. Patel RK, Sayers AE, Patrick NL, et al. A UK perspective on smartphone use amongst doctors within the surgical profession. Ann Med Surg (Lond). 2015; 4(2):107-12.

8. Franko Ol, Tirrell TF. Smartphone app use among medical providers in ACGME training programs. J Med Syst. 2012;36(5):3135-9.

9. Khatoon B, Hill KB, Walmsley AD. Dental students' uptake of mobile technologies. Br Dent J. 2014;216(12):669-73.

10. Suner A, Yilmaz Y, Piskin B. Mobile learning in dentistry: usage habits, attitudes and perceptions of undergraduate students. PeerJ. 2019;7:e7391.

11. Payne KB, Wharrad H, Watts K. Smartphone and medical related app use among medical students and junior doctors in the United Kingdom (UK): a regional survey. BMC Med Inform Decis Mak. 2012;12:121-31.

12. Masika MM, Omondi GB, Natembeya DS, et al. Use of mobile learning technology among final year medical students in Kenya. Pan Afr Med J. 2015;21:127-38.

13. Saxena P, Gupta SK, Mehrotra D, et al. Assessment of digital literacy and use of smart phones among central Indian dental students. J Oral Biol Craniofac Res. 2018:8(1):40-3.

14. Al-Ghamdi S. Popularity and impact of using smart devices in medicine: experiences in Saudi Arabia. BMC Public Health. 2018;18(1):531-8.

15. Jahanshir A, Karimialavijeh E, Sheikh H, et al. Smartphones and medical applications in the emergency department daily practice. Emerg (Tehran). 2017;5(1):e14.

16. Illiger K, Hupka M, von Jan U, et al. Mobile technologies: expectancy, usage, and acceptance of clinical staff and patients at a university medical center. JMIR Mhealth Uhealth. 2014;2(4):e42.

17. Grow JN, Vargo JD, Nazir N, et al. Smartphone applications in plastic surgery: a cross-sectional survey of 577 plastic surgeons, fellows, residents, and medical students. Aesthet Surg J. 2019;39(12):NP530-7.

18. Shaw $H$, Ellis $D A$, Kendrick $L R$, et al. Predicting smartphone operating system from personality and individual differences. Cyberpsychol Behav Soc Netw. 2016;19(12):727-32.

19. Li X, Xu ZR, Tang N, et al. Effect of intervention using a messaging app on compliance and duration of treatment in orthodontic patients. Clin Oral Investig. 2016;20(8):1849-59.

20. Hofer F, Haluza D. Are Austrian practitioners ready to use medical apps? Results of a validation study. BMC Med Inform Decis Mak. 2019;19(1):88-96.

21. Johnson AC, El Hajj SC, Perret JN, et al. Smartphones in medicine: emerging practices in an academic medical center. J Med Syst. 2015;39(1):164-9.

22. Mark D, Leonard C, Breen H, et al. Mobile phones in clinical practice: reducing the risk of bacterial contamination. Int J Clin Pract. 2014;68(9):1060-4.

23. Rung A, Warnke F, Mattheos N. Investigating the use of smartphones for learning purposes by Australian dental students. JMIR Mhealth Uhealth. 2014;2(2):e20.

24. Bullock A, Dimond R, Webb K, et al. How a mobile app supports the learning and practice of newly qualified doctors in the UK: an intervention study. BMC Med Educ. 2015;15:71-6.

25. Cox S, Pollock D, Rountree J, et al. Use of information and communication technology amongst New Zealand dental students. Eur J Dent Educ. 2016;20(3):135-41.

26. Greene $L R$, Spuur KM. Undergraduate use of medical radiation science mobile applications. Radiography (Lond). 2018;24(4):352-9.

27. Scarbecz M, DeSchepper EJ. Trends in first-year dental Students' information technology knowledge and use: results from a U.S. dental school in 2009, 2012, and 2017. J Dent Educ. 2018;82(12):1287-95.

28. Subhi Y, Bube SH, Rolskov Bojsen S, et al. Expert involvement and adherence to medical evidence in medical Mobile phone apps: a systematic review. JMIR Mhealth Uhealth. 2015;3(3):e79.

29. Buijink AW, Visser BJ, Marshall L. Medical apps for smartphones: lack of evidence undermines quality and safety. Evid Based Med. 2013;18(3):90-2.

30. Breland JY, Yeh VM, Yu J. Adherence to evidence-based guidelines among diabetes self-management apps. Transl Behav Med. 2013;3(3):277-86.

31. Abroms LC, Lee Westmaas J, Bontemps-Jones J, et al. A content analysis of popular smartphone apps for smoking cessation. Am J Prev Med. 2013; 45(6):732-6.
32. Pagoto SL, Schneider KL, Jojic M, et al. Weight loss using evidence-based strategies in mobile apps. Am J Prev Med. 2014:47(1):e2.

33. Breton ER, Fuemmeler BF, Abroms LC. Weight loss-there is an app for that! But does it adhere to evidence-informed practices? Transl Behav Med. 2011; 1(4):523-9.

34. Mobasheri MH, Johnston M, King D, et al. Smartphone breast applications what's the evidence? Breast. 2014;23(5):683-9.

35. Food and Drug Administration. Policy for Device Software Functions and Mobile Medical Applications. Guidance for Industry and Food and Drug Administration Staff. [https://www.fda.gov/regulatory-information/searchfda-guidance-documents/policy-device-software-functions-and-mobilemedical-applications]. Accessed 2 Jan 2020.

36. Boulos MN, Brewer AC, Karimkhani C, et al. Mobile medical and health apps: state of the art, concerns, regulatory control and certification. Online J Public Health Inform. 2014;5(3):229-51.

37. Zawati MH, Lang M. Mind the app: considerations for the future of Mobile health in Canada. JMIR Mhealth Uhealth. 2019;7(11):e15301.

38. Lewis TL, Wyatt JC. mHealth and mobile medical apps: a framework to assess risk and promote safer use. J Med Internet Res. 2014;16(9):e210.

\section{Publisher's Note}

Springer Nature remains neutral with regard to jurisdictional claims in published maps and institutional affiliations.

\section{Ready to submit your research? Choose BMC and benefit from:}

- fast, convenient online submission

- thorough peer review by experienced researchers in your field

- rapid publication on acceptance

- support for research data, including large and complex data types

- gold Open Access which fosters wider collaboration and increased citations

- maximum visibility for your research: over $100 \mathrm{M}$ website views per year

At BMC, research is always in progress.

Learn more biomedcentral.com/submissions 